\title{
Improvisational approaches to supervision dialogue
}

\author{
Sven Bjerstedt*
}

\begin{abstract}
The reflective processes in which supervisors and doctoral students indulge together may be improvisatory to an important extent. Based on literature review and a small interview study, I argue that there are important similarities between musical improvisation and supervision dialogue regarding, for instance, the need for structure as well as continuous impulse fluidity and the need for receptivity as well as initiative. In musical improvisation as well as in supervision, it is crucial to be able to relate simultaneously, by way of qualities such as openness, wholeness, and listening, to both internal and external impulses, to both structural and communicative aspects, and to both one's own individuality and the tradition in which one is situated. In the concluding discussion, I identify a number of implications for the education of doctoral supervisors.
\end{abstract}

Key words: supervision, improvisation, dialogue, conversation

\section{INTRODUCTION}

Supervision poses a number of educational challenges many of which relate to its predominant format: interpersonal dialogue. In supervision dialogue, the supervisor and the doctoral student arguably discover the future created by their actions as it unfolds; they navigate through the discrepancies of a complex system that is constantly evolving; they face unstructured tasks through combining incomplete and disparate knowledge and proposing multiple interpretations; they solve problems in situ, interweaving general concepts with the demands of the particular situation; they address indeterminate tasks with resourcefulness and pragmatism; they discover new routes and invent novel responses without a prescripted plan and without knowing the outcomes with certainty; they experience the need to balance structure and freedom, autonomy and interdependence, as well as surrender and control; and in their dedication to creation and innovation, they continously make a large number of decisions. In brief, they are hopeful, believing in the human potential to think freshly, to invent new solutions and to create something interesting and novel. Arguably, all these activities require trust, flexibility, experimentation, spontaneity, creativity and a willingness to suspend control and surrender to the flow of the ongoing activity.

The aim of this reflective essay is to investigate a way of understanding how doctoral supervision may function and, based on this understanding, how it may be developed and improved. My point of departure is the notion that the reflective processes in which supervisors and doctoral students indulge together may be improvisatory to an important extent. I will attempt to do this by way of analogy/model/metaphor, that makes use of thought structures ordinarily ascribed to musical improvisation.

\footnotetext{
* Correspondence to: Bjerstedt Sven, sven.bjerstedt@thm.lu.se

The submission categories 'Articles' and 'Reflections' are peer reviewed. The other types of submissions are reviewed solely by the editorial board. See www.hogreutbildning.se ISSN 2000-7558

(C)2017 Sven Bjerstedt. This is an Open Access article distributed under the terms of the Creative Commons Attribution-NonCommercial 4.0 International License (https://creativecommons.org/licenses/by-nc/4.0/), allowing third parties to share their work (copy, distribute, transmit) and to adapt it, under the condition that the authors are given credit, that the work is not used for commercial purposes, and that in the event of reuse or distribution, the terms of this license are made clear. Citation: Sven Bjerstedt (2017) «Improvisational approaches to supervision dialogue». Högre utbildning, 7, 2: 63-76. http://dx.doi.org/10.23865/hu.v7.1076
} 
Needless to say, the relation between a supervisor and a doctoral student is characterized by a certain complexity. Like all relations, it is at the same time situation specific and structural. In this essay, the structural aspects of supervision processes will not be dealt with in depth; rather, my focus will be on how doctoral supervision may profit from a particular kind of situation specific approach, based on and inspired by a perception of musical improvisation, particularly in jazz.

In a sense, this combination of perspectives may be viewed as a reflection of my own experiences from the two fields of scholarship and music, as well as of the conviction borne upon me due to these experiences regarding the important ways in which the bi-directionality between scholastic and artistic knowledge can function. For several decades I have worked as a jazz pianist as well as an academic teacher and - in later years - a doctoral supervisor. Even though it was not quick, my way from jazz to academia was, in a sense, rather straightforward. When the opportunity arose to undertake a $\mathrm{PhD}$ project about jazz improvisation, I jumped at it. Through processes of widened, deepened and prolonged reflection, my scholarly efforts contributed something substantial in return, impacting my artistic practice significantly. The lessons from the arts to research were no less important. Influences run both ways. In other contexts (Bjerstedt, 20I5a, 20I5b) I have attempted analyses of what reflection on jazz improvisation may bring to qualitative research methodology.

The present essay is structured in three sections. In the first section, I try to demonstrate through a literature review that the notion of an analogy between doctoral supervision dialogue and musical improvisation is no whim; rather, its relevance and fruitfulness are thoroughly substantiated in previous writings. In the second section, the results of a small interview study are presented and analysed. The aim of this section is to further investigate the potential of the analogy between supervision dialogue and improvisation: what may become visible and what may become possible when the similarities in thought structure are taken in to consideration? In the concluding section I discuss requirements and obstacles with regard to supervisors' learning and development of improvisational skills, on a personal, an educational and an institutional level.

The relation between supervisor and doctoral student is arguably asymmetrical when viewed from a power perspective. This may affect their interchange of ideas so that, in the words of Zali Gurevitch (200I), instead of being a "dialectical dialogue", it may rather resemble closed forms of speech "with little space between for improvisation and open play" (p. Ioo). Arguably, in order to avoid such closed forms of speech in doctoral supervision dialogues, an intentional focus on alternative approaches may prove fruitful. Barbara M. Grant (20I0) proposes an improvisational approach in doctoral supervision as a way of challenging what she considers "a significant archetype for supervision" (p. 272), namely, a Master-Slave figure based in Hegel's writings (Hegel, 1977 [1807]).

Based on my own experiences as a musical performer in several contexts, I vigorously endorse the potential of improvisational approaches to challenge and overcome hierarchical power relations. A brief autoethnographical narrative may shed light on how this may take place in the context of improvised music. Some thirty years ago, as a quite young jazz pianist I had the opportunity to perform recurrently with renowned musicians of older generations such as the Swedish clarinetist Putte Wickman (b. 1924); Sweden's foremost jazz ambassador and former Duke Ellington sideman, trumpeter Rolf Ericson (b. 1922); and the American saxophonist Benny Waters (b. 1902), a true nestor of jazz who could look back on 
a musical career starting in the I920s together with iconicized legends such as King Oliver, Louis Armstrong and Fletcher Henderson. Needless to say, the vast difference in professional experience and authority between each of these world famous performers and the other band members - who were all of my own age - was awe-inspiring. The power relations were definitely not symmetrical.

However, the consistent focus on improvisational performance in the present moment, which is a typical feature of jazz (Bjerstedt, 20I4), successfully challenged this asymmetry. Far from turning into examples of a Master-Slave archetype, the concerts where these revered heroes played together with a bunch of promising youngsters emerged as collaborations, or conversations, of fellow musicians. They were characterized by openness, encouragement, mutual trust and shared responsibilities. All performers were granted ample solo space, and I had a strong impression of an on-going musical dialogue that was very much on equal terms. Benny Waters, who was 88 at the time, turned on his portable cassette recorder beneath his chair before picking up his horn for the next set, explaining to me: "I like to listen to my own playing the next day in my hotel room, to see what I can improve on."

Most improvising musicians will undoubtedly be able to relate similar experiences. It has been argued, for instance, that the learning processes among young musicians working with Miles Davis were promoted to a high degree by Davis's openness and ability to deliver the artistic individuality of each improviser (Bjerstedt, 20I4, p. 289). In later years, mirroring my youth experiences, I have often played together with less experienced young musicians in improvisational performances that I believe have been characterized in the same way by openness, encouragement, trust and shared responsibilities.

Based then, on my own experiences as a musical improviser, a former doctoral student, and a supervisor, I suggest that improvisational approaches to doctoral supervision may be very useful in general - regardless of whether the supervision relation is viewed from a power perspective or from complementary and perhaps more complex perspectives (cf. Lee, 2008).

\section{LITERATURE REVIEW: IMPROVISATION IN LIFE, IN MUSIC, IN REFLECTIVE PRACTICE, AND IN SUPERVISION}

It might be argued that the need to improvise, as well as the ability to do so, make up an important part of our human life conditions. Gilbert Ryle (1976) argues that our everyday actions in response to life's ever-changing conditions always require some degree of improvisation:

the vast majority of things that happen in the universe are in high or low degree unprecedented, unpredictable, and never to be repeated. [...] To a partly novel situation the response is necessarily partly novel, else it is not a response. (p. 73)

Mary C. Bateson (1990) suggests that jazz is a suitable metaphor for life, which is an improvisatory art: "we combine familiar and unfamiliar components in response to new situations, following an underlying grammar and an evolving aesthetic" (p. 3). The improvisatory nature of human action is perhaps especially obvious in communicative activity; Stephen Nachmanovitch (1990) holds that the activity of "instantaneous creation is as ordinary to us as breathing" and that every conversation is "a form of jazz" (p. I7). Philip Alperson (20Io), arguing that "improvisation would seem to be a feature of most, if not all, directed human 
thought and action", offers a generalized characterization of improvisation as a spontaneous activity that is goal-directed:

In a very general sense, we can think of improvisation as a kind of goal-directed activity ('I need to find something to get this boulder out of the way'), but what makes the activity improvisatory is the sense that what is being done is being done on the fly ('Maybe I can use this branch as a lever to move the rock'). (p. 273)

In improvisation, one is expected to create something coherent although the future is largely unknown and there are no clear prescriptions of what is to be done. Crucial aspects of improvisation then, are the abilities to create innovations in order to save situations and to make do with the resources at hand, formulated by Karl E. Weick (1998; with reference to Claude Lévi-Strauss [1966]) as "skills of bricolage" (p. 548).

Even though improvised music may be defined as music that is to a certain extent not foreseeable (Gagel, 20IO), the musical context often emerges as an important factor. Alperson (1984) points out that "[e]ven the freest improviser, far from creating ex nihilo, improvises against some sort of musical context" (p. 22). Indeed, the act of improvising may be seen as a combination of (i) preparing materials and strategies, and (ii) implementing them, often in accordance with a certain system of conventions. According to Paul F. Berliner (1994), "improvisation involves reworking precomposed material and designs in relation to unanticipated ideas conceived, shaped, and transformed under the special conditions of performance, thereby adding unique features to every creation" (p. 24I); furthermore, improvisational ability depends on "a broad base of musical knowledge, including myriad conventions that contribute to formulating ideas logically, cogently, and expressively" (p. 492). Aaron L. Berkowitz (20I0), considering such kinds of idiomatic musical improvisation that are learned through "immersion" in a certain musical system, holds that the ability to improvise in a certain style "relies on an intimate knowledge of the musical elements, processes, and forms of that style" (p. xv); on the same note, Carol S. Gould and Kenneth Keaton (2000) argue that "all musical improvisation relies on the foundations of the particular musical style in which the work exists" (p. 146). Learners of improvisation need access to experienced practitioners through legitimate peripheral participation (Lave \& Wenger, 199I). Becoming a knowledgeable member and learning the code takes place in jam sessions and several other contexts, "through formal and informal meetings, conversations, stories, myths, rituals, etc." (Barrett, 1998, p. 616). While many - if not all - musical contexts include improvisational features to a certain extent, jazz emerges as an archetypical example many writers draw on in analogies between musical improvisation and other activities.

Musical improvisation may be characterized as a skilled and creative process in which musical thinking and performing occur simultaneously (Bailey, 1992, p. 66). Frank J. Barrett (1998) points out that errors, i.e., discrepancies between intention and action, are used as creative departures and sources of discovery, so that "looking backward, the 'wrong' notes appear intentional" (p. 6Io). Barrett interprets this phenomenon as "an aesthetic of imperfection and an aesthetic of forgiveness that construes errors as a source of learning that might open new lines of inquiry" (p. 619). In the words of Weick (1998), "[i]n jazz improvisation people act in order to think, which imparts a flavor of retrospective sensemaking to improvisation" (p. 547).

Another important feature of jazz improvisation, preparation, is emphasized by Barrett (1998): "Learning to play jazz is a matter of learning the theory and rules that govern 
musical progressions. [Jazz players] study other players' strategic thought process [...] [S]uccessful jazz performances are not haphazard or accidental. Musicians prepare themselves to be spontaneous" (pp. 606, 607, 620). In brief, any views of improvisation as lacking in preparation are seriously amiss and would arguably meet with protest from anyone acquainted with the musical improviser's craft.

Being prepared, however, is far from enough; being open is equally important. Apart from requirements such as experience, security, knowledge of tradition, theory and repertoire, as well as technical and mental preparedness, several other abilities emerge as equally central to the musical improviser. Barrett (1998) points out that "too much reliance on learned patterns $[\ldots]$ tends to limit the risk-taking necessary for creative improvisation"; in order not to fall back on habitual responses, improvisers need to explore the limits of their knowledge and comfort level (pp. 607-608). Among the most crucial faculties for jazz improvisation is the complex ability to relate simultaneously, by way of qualities such as openness, wholeness, and listening, to both internal and external impulses, to both structural and communicative aspects of the music, and to both one's own individuality and the tradition in which one is situated (Bjerstedt, 20I4).

The act of improvising requires an empathic ability to engage in intense listening (Bailey, 1992) as well as flexibility, courage and tolerance for ambiguity (Berliner, 1994). Improvisers must indulge in a continuous give-and-take through simultaneously (i) formulating their own independent ideas and (ii) listening to and interacting with their fellow musicians. Typically, they "take turns soloing and supporting other soloists", "interpret others' playing, anticipate likely future directions, make instantaneous decisions" as well as "see beyond the player's current vision, perhaps provoking the soloist in different direction" (Barrett, I998, pp. 6I6-617). Discussing this requirement of receptivity, Berliner (1994) quotes jazz trumpeter Wynton Marsalis who employs an analogy with verbal conversation and "the worst people to talk to" in order to shed light on these musical requirements: "When you're talking, they're thinking about what they are going to tell you next, instead of listening to what you're saying" (p. 4OI).

Based on Saint Augustine's (1990 [n.d.]) and Paul Ricoeur's (1984) writings on temporality, I have analysed the musical act of improvising in terms of a multi-directed awareness of pastpresent-future perspectives; it includes both transformation of preexisting materials and multidirectionality in the present moment as well as conveying improvisationally created coherence on individual and collective levels (Bjerstedt, 20I4, pp. 324-329).

Importantly, improvisation is also a crucial feature in temporal art forms other than music, e.g. theatre. In a 1975 interview, the theatre director Ariane Mnouchkine considered the main difference between her work and that of other directors to be that "she had no foreknowledge of what could happen in the rehearsal and in improvisation sessions at the Theâtre du Soleil. Instead her role was to explore and create in company with actors, designers, etc." (Bradby, 1984, p. 19I). I believe that Mnouchkine's stance may be interpreted in part as an exercise in openness to the demands of the present situation, similar to that of jazz improvisers. In actor training, improvisation is a crucial tool; for instance, clown exercises may be employed with the explicit aim to let students learn how to enhance and make productive use of their mistakes, instead of trying to hide them (Lundberg, 1989, p. 60).

Inspired by Bateson's (1990) perspective, Penny Oldfather and Jane West (1994) address methodological issues in a playful attempt to shed light on the nature of qualitative inquiry through a metaphor of qualitative research as jazz. Oldfather and West point out that jazz music 
is characterized by its unifying structures and common body of knowledge as well as by the open-endedness of its improvisatory nature. The uniqueness of each improvisation, they hold, corresponds to the adaptive methodologies and contextually bound findings of each qualitative inquiry. I have pointed out a number of further similarities between the thought structures involved in jazz improvisation and qualitative research (Bjerstedt, 20I5b).

All improvisational dialogue requires speaking, listening, and responding (Gurevitch, 200I; Grant, 20IO). Qualitative interviews may be put forward as a convincing example of a context where improvisational features may play an important role (Bjerstedt, 20I5a). Importantly and in a way reminiscent of the example mentioned above of how clown exercises may help actor students make productive use of mistakes - Svend Brinkmann (2013) argues that there is much to learn from interviews that contain "misunderstandings or other breaks in the conversational flow": "Aspects that stand out as strange may often prove to be valuable to understanding how talking about the subject matter in a specific way constructs what we may know about it" (pp. 65-66).

Therapy also emerges as a context marked by improvisation. The therapist's participation in a session is described by Bradford P. Keeney (1990) as "an invitation to improvise":

Since the therapist never knows exactly what the client will say at any given moment, he or she cannot rely exclusively upon previously designed lines, patterns, or scripts [...] every particular utterance in a session offers a unique opportunity for improvisation, invention, innovation, or more simply, change. (p. I)

Furthermore, organizational practices may be seen as improvisational to a significant extent. Weick (1992) suggests that a focus on understanding how successful musical improvisation works may help organizational theorists understand how the development of qualities such as flexibility, confidence, self-esteem, and self-identity can be facilitated (p. 408). Weick (1998) points out that "[i]mprovisation is a mixture of the precomposed and the spontaneous, just as organizational action mixes together some proportion of control with innovation, exploitation with exploration, routine with nonroutine, automatic with controlled" (p. 55I). Barrett (1998), posing the questions, "are there ways to socialize a mindset that nurtures spontaneity, creativity, experimentation, and dynamic synchronization in organizations? What practices and structures can we implement that might emulate what happens when jazz bands improvise?" (p. 6r7), points out the similarities between organizational and jazz practices: "Jazz players do what managers find themselves doing; fabricating and inventing novel responses without a prescripted plan and without certainty of outcomes; discovering the future that their action creates as it unfolds" (p. 605).

As a preliminary indication of some of the benefits that improvisational approaches may have in contexts of doctoral supervision, I include a few points suggested by scholars focusing on the field of organizational theory. Iain L. Mangham and Annie Pye (1991) discuss a number of features that are common to managing and jazz improvisation: simultaneous reflection and creation; simultaneous rule creation and rule following; patterns of mutually expected responses; action informed by codes; continuous mixing of the expected with the novel; and heavy reliance on intuitive grasp and imagination (pp. I8-79).

Barrett (1998) points out the following features of jazz improvisation as relevant to organizational design: efforts to interrupt habit patterns; errors as a source of learning; minimal structures that allow maximum flexibility; continual negotiation and dialogue toward dynamic 
synchronization; retrospective sense-making; membership in a community of practice; and taking turns soloing and supporting (p. 606).

Weick (1998) also lists a number of dimensions of jazz improvisation that may be relevant to organizational theory: e.g., degrees of improvisation (interpretation-embellishment-variationimprovisation); the ways in which "mistakes" provide the platform for "saves" that create innovations; and skills of bricolage that enable people to make do with whatever resources are at hand (p. 548). Mutatis mutandis, features of jazz improvisation such as those listed by Mangham and Pye (199I), Barrett (1998) and Weick (1998) may well prove relevant to doctoral supervision as well; I will return to this point in the concluding section of this essay.

The roles and functions of improvisation in educational contexts have been the subject of several studies, e.g., an extensive ongoing Norwegian project (Holdhus et al., 20I6). Mature academic work may be seen as "a creative process of trial and error, [...] of clarity and confusion" (Grant, 20IO, p. 283). It is reasonable that these features should also characterize academic training in general as well as, for instance, in specific training contexts such as doctoral supervision dialogue. "Thinking through the metaphor of improvisation," Grant (2010) contends, "directs our attention towards a vibrant moment in supervision, one in which reciprocity between supervisor and student is a critical feature"; and although it "takes courage" to participate in this, it can be "joyful and rewarding as well" (p. 284).

One of few Swedish handbook writers on doctoral supervision to touch upon improvisational approaches in supervision dialogue is Hans Birnik (20I0): "With the term improvisation I refer to the supervisor's ability to leave her usual patterns of thinking and acting. [...] Improvisation may help the client see a problem or shed light on a question in a qualitatively new way" (p. 89; my translation). Dominic Ingemark (2012) presents and discusses a model of supervision dialogue inspired by jazz improvisation that may challenge the power relations between the supervisor and the doctoral candidate. He describes how creative moments in supervision characterized by improvisation, "an interplay based on a sensitive ear", may render "a strong positive feeling, almost a kind of supreme happiness" (pp. 6-7; my translation).

Grant (20I0) describes improvisational supervisory moments as having "a dynamic, playful and more mutual character" (p. 27I). Her analysis of an empirical study of a supervision dialogue is based on Gurevitch's (200I) exploration of "the poetics of dialogue" where speech is pulled into an "associative state of sociality" (p. 99). Grant (2010) points out that "the very fragility of improvisation may also be the condition of its creativity" (p. 275), and that, because of this fragility, improvisational dialogues "occur on the edge of chaos and incoherence, and a collapse from betweenness back to the agonism of master-slave is always possible" (p. 28I).

On the same note as Brinkmann's (2013) observation that the qualitative researcher may have much to learn from "breaks in the conversational flow" (p. 65), Grant (2010) states - based on her empirical study - that improvisational exchanges in supervision "include interruptions, aside and humour", and she points out: "Crucially, they take time" (p. 277).

Esther Fitzpatrick and Katie Fitzpatrick (2015) present an uncommon way of including improvisation in research supervision:

We started writing poems to reflect our thoughts and feelings about the project and about research more generally. These poems are not meant to be part of the research project itself but, rather, a way of communicating about research that values emotionality, creativity, and poetic voice. (p. 50) 
Reflecting over the implications of this practice of writing poems within the framework of doctoral supervision, Fitzpatrick and Fitzpatrick (2015) conclude that the poems "allowed us to explore writing together in a collaborative (rather than hierarchical) sense", that the poems "demonstrate our growing trust in each other", and that "[t]hrough our improvisation with poetry, we respected each other's vulnerability" (pp. 55-56).

\section{IMPROVISATIONAL APPROACHES TO SUPERVISION DIALOGUE: AN INTERVIEW STUDY}

I conducted a small interview investigation in order to shed further light on how improvisation may function in the context of supervision dialogues and to further evaluate the potential of the analogy between supervision dialogue and improvisation. What may become visible and what may become possible when the similarities in thought structure are taken into consideration? I interviewed in email correspondences two female doctoral supervisors in Music Education (anonymized as Diana and Eve) and two male doctoral supervisors in Theatre (Adam and Charles) at the Malmö Faculty of Fine and Performing Arts, Lund University, Sweden. The questionnaire contained five questions. The interviews were conducted in Swedish; the translations of the answers are mine. In this section I will present a number of viewpoints and formulations that I regard as particularly interesting.

Dialogue as improvisation. The informants agree that improvisation may be seen as a common feature of dialogue. Diana views improvisation as "a natural part of most educational situations," and Adam says: "All conversations seem to include improvisational elements and unexpected turns [where] new knowledge can emerge." On the same note, when asked what improvisational features in supervision dialogues may require on the part of the supervisor, Adam replies: "None other than in normal conversation, I believe."

Listening. However, not all of them usually think of this feature in terms of improvisation; Eve reflects that she has not been "thinking of it as improvisation - more as active listening." In response to the question about requirements on the part of the supervisor, Eve points out: "First and foremost the ability to listen."

Charles views listening as the essence of supervision, stating that " $[\mathrm{t}] \mathrm{o}$ be in a listening mode and to be open to what emerges in dialogue is the basis for a good conversation."

Preparedness. Another central requirement on the part of the supervisor is preparedness to improvise based on questions and needs that turn up during conversations. Eve views this as a preparedness "to follow up on the direction that the conversation will take," Charles as an openness "to the doctoral student's needs and questions." Charles further points out that "[y]ou are in a process of trial; [...] you must start with the situation and use the doctoral student's questions as a point of departure."

Experience. In Diana's view, the supervisor's experience is the most important requirement: ability to improvise in supervision dialogue requires "that the supervisor has a number of methods for discovering, investigating and uncovering different alternatives by way of improvisation. At the end of the day, then, it is a question of experience and competence."

Doubt and trust. Focusing on the doctoral student's perspective, the dynamics of doubt and trust emerge as crucial to supervision dialogue. Several informants point to trust as the main benefit of improvisational features. According to Eve, "[a] kind of trust can be built" based on improvisational dialogue; Adam agrees that "[t]he doctoral student's trust increases." Diana 
finds that improvisational dialogue "creates possibilities for risk taking and security." From the opposite perspective, one reason for improvisation in supervision dialogue may be based on the doubt that he or she experiences, according to Adam: "It is often due to the doctoral students doubting their own ability."

Investigative mode. One important function of improvisation is formulated as the task of investigating 'likes' and 'unlikes.' In Charles's words, "It is as much about finding common ground as about naming differences in how you view art and learning. And to encourage an investigative work mode."

Independence. Diana points out that the investigative mode that may be spurred by improvisational dialogue is an important step towards the doctoral student's independence: "Mutual knowledge making by way of improvisation enables the doctoral student to take control of her own learning."

Open up alternatives. While one aspect of improvisational openness can be formulated in terms of receptivity and listening, the informants also point to a more dynamic kind of openness that may help the supervisor and doctoral students to include new, unexpected or alternative perspectives. Diana views this as the most important feature of improvisational dialogue, and she emphasizes that this openness often will manifest itself in especially important moments during the dialogue, which she terms 'cross-roads,' or 'micro-moments.' Diana says: 'The work on a thesis has many cross-roads. At all these cross-roads there are possibilities to investigate, to experiment, [...] which requires improvisation in order to transcend norms, [...] to have the courage to lose one's way together, [...] to open up alternatives lines of thought." A micromoment, Diana explains, "occurs every time there is a crack in that which was expected, or when something takes an unexpected turn;" micro-moments "often emerge where improvisation is required in order to deal with the situation but also in order to explore that which has been taken for granted." To her, losing one's way together may be the most important function of improvisational supervision dialogue: "I often find that I can use my improvisational skills when I have the possibility to bring other perspectives to the supervision situation."

Difficulties to proceed. Several informants also point to possible negative consequences of improvisational features in supervision dialogues. The main point in these perceived disadvantages is that, in Charles's words, "[i]t may be difficult to direct the research process forward." Diana agrees that there may be a risk that "the doctoral student and supervisor cannot proceed in the process; 'still confused, though on a higher level,' as my mentor would say." According to Adam, "[t]he supervisor may escape from the subject or avoid complications or avoid showing their incompetence by moving the conversation to 'safe' ground. In improvisation there is a danger of repeating oneself."

\section{CONCLUDING REMARKS}

Based on these few email interviews, improvisational approaches emerge as a fruitful perspective on how supervision dialogue may function. In this paragraph, I summarize a number of the interviewees' perspectives that I find particularly interesting. Indeed, all conversation may be seen as improvisatory. Improvisational supervision dialogue may be viewed as active listening, as an openness to the doctoral student's needs and questions and as a preparedness to use these questions as a point of departure and follow up on the direction that the conversation will take. The supervision dialogue may be seen as a process of discovery. The ability to improvise in 


\section{S. Bjerstedt}

conversation is required in order to build trust, to identify commonalities and differences and to encourage an investigative work mode. It may be used to explore that which has been taken for granted, to transcend norms and to open up alternative lines of thought. Improvisational conversation may be needed when doctoral students doubt their own ability, in order to promote confidence and independence. An improvisatory stance arguably requires experience and competence in the supervisor.

Needless to say, I do not consider it meaningful or even possible to draw conclusions of a general nature on conversational dynamics from the interview responses. Supervision dialogues do not proceed in accordance with mechanisms; they develop in different and unpredictable ways. Notwithstanding, several interview utterances indicate considerable similarities between musical improvisation and supervision dialogue. These similarities would seem to regard, for instance, the need for structure as well as continuous impulse fluidity and the need for receptivity as well as initiative. In particular, it is illuminating to observe how knowledge, meaning, and understanding can be generated as direct consequences of "breaks in the conversational flow" (Brinkmann, 2013, p. 65).

Another brief autoethnographical narrative may exemplify how an improvisational approach to doctoral supervision may function in a concrete situation. In this story, I was the doctoral student. For a long time, I had been struggling with the problem that out of the multitude of theoretical references that I found highly relevant to my field of inquiry, far from all would actually serve as analytical tools in my discussion of actual research findings. According to one very common view in my discipline as in several others, this was a no-no; the researcher should never carry any theoretical luggage other than that which is made use of in relation to the empirical data. The head of subject would often return to this perspective, presenting it as a problem that I needed to solve. I must admit that I was stubbornly reluctant to throw away a number of ladders that I considered pertinent in principle to an emerging field of inquiry. My supervisor had not addressed this issue, however, but at one meeting I brought it up with her. After a few seconds of thought, she directed my attention to the concept of prolonged engagement in Lincoln and Guba's Naturalistic inquiry (1985), suggesting that the prolongation of a researcher's engagement with a field of inquiry may be seen as extended over several projects. To me, this was something of an epiphany. As a consequence, based on this notion of the researcher's prolonged engagement, I eventually argued in my dissertation that such parts of the theoretical infantry that were not commanded to battle within the frame of that particular investigation would certainly prove to be relevant in related future research projects such as those I outlined in the concluding chapter of my book. As an additional result of this perspective, which was originally brought up in that improvised on-the-spot comment by my supervisor, I was able in a later essay on research methodology to develop and discuss a four-part model of the concept of prolonged engagement (Lincoln \& Guba, 1985) with regard to multiple research projects over an extended time period (Bjerstedt, 2015b, p. 44).

I would argue that what my supervisor did in the moment related in this story was very much in tune with the perspectives on improvisation put forward in this article. Undoubtedly, against the background of the common view on superfluous theoretical luggage, her comment may be seen as an example of flexibility, courage, and tolerance for ambiguity (Berliner, 1998) as well as of risk-taking (Barrett, 1998). Furthermore, her comment was clearly improvised against a context 
(Alperson, 1984, p. 22), namely, her and my understanding of Lincoln and Guba's concept. This understanding may be seen as a form of precomposed material which was reworked in an improvisational manner in relation to an unanticipated idea (Berliner, 1994, p. 24I). I also believe that establishing this common theoretical ground through previous course and supervision meetings, as well as getting acquainted with each other' interests, perspectives and ways of thinking during previous discussions, may be seen as pertinent aspects of our preparation to be spontaneous (Barrett, 1998, p. 620). Not least important, from my own point of view, were the ways in which this improvised comment helped me develop confidence, self-esteem, and self-identity (Weick, 1992, p. 408).

How, then, can supervisors "prepare themselves to be spontaneous" (Barrett, 1998, p. 620)? In the first section of this essay I argued that a musical improviser must meet requirements such as experience, security, knowledge of tradition, theory and repertoire, as well as technical and mental preparedness. In addition, an improviser must be able to relate simultaneously, by way of qualities such as openness, wholeness, and listening, to both internal and external impulses, to both structural and communicative aspects, and to both one's own individuality and the tradition in which one is situated.

I suggest that a modified list of requirements pace Mangham and Pye (1991), Barrett (1998) and Weick (1998) emerges as a set of relevant qualities and abilities in the context of doctoral supervision. Arguably, these include willingness, confidence and competence to:

- interrupt habit patterns and depart from routine;

- mix the expected with the novel;

- reflect and create simultaneously;

- create rules and follow rules simultaneously;

- identify codes as a source of action;

- embrace errors as a source of learning;

- agree on and make use of minimal (but rich and meaningful) structures that allow maximum flexibility;

- make use of patterns of mutual expected responses, continual negotiation and dialogue toward dynamic synchronization;

- rely on intuitive grasp and imagination;

- rely on retrospective sense-making;

- embrace "hanging out" as a way toward membership in a community of practice;

- take turns soloing and supporting;

- pay attention to and build on the other's performance;

- set up interesting possibilities for one another;

- act in real time without planning and rehearsing;

- identify and make do with the resources at hand;

- recognize relevant previous experience;

- deal with nonroutine activities;

- maintain each other's tempo;

- focus on coordination in the present moment, without distraction by thoughts on past and future; and

- focus on process rather than product, development rather than outcome. 


\section{S. Bjerstedt}

Heavy as these requirements may seem, I would argue that they are all applicable and relevant to the supervisor's task through, among other things, their potential to nurture an investigative mode, to turn doubt into trust and to open up alternative lines of thought and action.

There could and should be several ways to accomplish them. Education of doctoral supervisors could include taking part of and discussing second hand analyses of how musical improvisers think (e.g., Berliner, 1994; Monson, 1996; Bjerstedt, 2014); or it could include taking part of and discussing first hand encounters with musicians (e.g., lectures, interviews, workshops). First and foremost, however, an improvisational mindset ought to be embraced on several levels of research communities. I suggest that the advantages of improvisational approaches ought to be addressed and supported in supervisors' educational training as well as by mentors, research environments and institutions. Just as is the case with musical improvisers, legitimate peripheral participation is key. The learning and development of supervisors' improvisational skills must arguably take place in numerous contexts: "through formal and informal meetings, conversations, stories, myths, rituals, etc.” (Barrett, 1998, p. 616).

Admittedly, this may meet with difficulties; for instance, many individuals may have views regarding jazz improvisation that are marked by alienation, apathy, aversion even. This might possibly constitute an initial obstacle that may hamper their willingness to embrace the perspectives I have advocated in this essay. However, I believe that the benefits of an improvisational mindset will not only eventually emerge as an important asset to the supervisor's profession but may also nurture a positive interest in the qualities and abilities displayed by musical improvisers.

At the outset of this article, it was pointed out that relations - including doctoral supervision are at the same time situation specific and structural. If the positive importance of situation specific, improvisational approaches to doctoral supervision is acknowledged, this may have practical consequences regarding structural aspects of supervision. Doctoral supervision takes place within an institutional framework. I find myself in agreement with Grant's (2010) observation that "the institution's role with respect to making space for improvisation" (p. 285) must be considered. Requirements and obstacles with regard to supervisors' development of improvisational skills need to be discussed on a personal, an educational and an institutional level. As I have argued above, several didactic loci may emerge as relevant.

\section{AUTHOR PRESENTATION}

Sven Bjerstedt (b. 1962) holds a PhD in music education research and is Assistant Dean of the Faculty of Fine and Performing Arts at Lund University, Sweden. He is also a jazz pianist and a senior lecturer in music at Malmö Theatre Academy (Lund University). Bjerstedt's PhD thesis (20I4) was a study of storytelling in the field of jazz improvisation, and his recent book, Skådespelarens musikalitet (2017), examines musicality in the field of spoken theatre.

\section{REFERENCES}

Alperson, Philip (1984). On musical improvisation. Journal of Aesthetics and Art Criticism, 43(I), I7-29. Alperson, Philip (20I0). A topography of improvisation. Journal of Aesthetics and Art Criticism, 68(3), 273-280.

Augustine (1990 [n.d.]). The confessions. Chicago: Encyclopædia Britannica.

Bailey, Derek (1993). Improvisation: Its nature and practice in music. New York: Da Capo Press.

Barrett, Frank J. (1998). Creativity and improvisation in jazz and organisations: Implications for organizational learning. Organization Science, 9(5), 605-622. 
Bateson, Mary C. (1990). Composing a life. New York: Penguin.

Berkowitz, Aaron L. (2010). The improvising mind: Cognition and creativity in the musical moment. Oxford: Oxford University Press.

Berliner, Paul F. (1994). Thinking in jazz: The infinite art of improvisation. Chicago \& London: The University of Chicago Press.

Birnik, Hans (2010). Handledande samtal. (Supervision dialogues.) Lund: Studentlitteratur.

Bjerstedt, Sven (20I4). Storytelling in jazz improvisation: Implications of a rich intermedial metaphor. Malmö: Lund University, Malmö Academy of Music.

Bjerstedt, Sven (20I5a). Qualitative inquiry, reflective practice and jazz improvisation. Reflective Practice, I6(2), 2I8-229.

Bjerstedt, Sven (2015b). It is all process. In Liora Bresler (Ed.), Beyond methods: Lessons from the arts to qualitative research (pp. 37-47). Malmö: Lund University, Malmö Academy of Music.

Bradby, David (1984). Modern French Drama 1940-1980. Cambridge, UK: Cambridge University Press.

Brinkmann, Svend (2013). Qualitative interviewing: Understanding qualitative research. Oxford: Oxford University Press.

Fitzpatrick, Esther, \& Fitzpatrick, Katie (2015). Disturbing the divide: Poetry as improvisation to disorder power relationships in research supervision. Qualitative Inquiry, 2I(I), 50-58.

Gagel, Reinhard (2010). Improvisation als soziale Kunst: Überlegungen zum künstlerischen und didaktischen Umgang mit improvisatorischer Kreativität. Mainz: Schott Music.

Gould, Carol S., \& Keaton, Kenneth (2000). The essential role of improvisation in musical performances. Journal of Aesthetics and Art Criticism, 58(2), I43-I48.

Grant, Barbara M. (2010). Improvising together: The play of dialogue in humanities supervision. Arts and Humanities in Higher Education, 9, 27I-288.

Gurevitch, Zali (200I). Dialectical dialogue: The struggle for speech, repressive silence, and the shift to multiplicity. British Journal of Sociology, 52(I) (March 200I), 87-IO4.

Hastrup, Kirsten (1999). Viljen til viden: En humanistisk grundbog. (The will to know: A basic book of humanism.) København: Gyldendal.

Hegel, Georg Wilhelm Friedrich (1977 [1807]). Phenomenology of spirit. (Trans. A. V. Miller). Oxford: Oxford University Press.

Holdhus, Kari, et al. (2016). Improvisation in teaching and education: Roots and applications. Cogent Education, 3(I204I42), I-I7.

Ingemark, Dominic (20I2). En trevlig dialog eller tvingande monolog? (A nice dialogue or imperative monologue?) (Course paper, Research supervision - Introduction.) Lund: Lund University (CED).

Keeney, Bradford P. (1990). Improvisational therapy. New York: Guilford.

Lave, Jean, \& Wenger, Etienne (1991). Situated learning: Legitimate peripheral participation. Cambridge, UK: Cambridge University Press.

Lee, Anne (2008). How are doctoral students supervised? Concepts of doctoral research supervision. Studies in Higher Education, 33(3), 267-281.

Lévi-Strauss, Claude (1966). The savage mind. Chicago: University of Chicago Press.

Lincoln, Y. S., \& Guba, E. G. (1985). Naturalistic inquiry. Newbury Park, CA: SAGE.

Lundberg, Nina (1989). Clowner: En dokumentation av ett projekt på Teaterhögskolan i Malmö. (Clowns: Documentation of a project at Malmö Theatre Academy.) Malmö: Lund University, Malmö Theatre Academy.

Mangham, Iain L., \& Pye, Annie (I99I). The doing of managing. Oxford: Blackwell.

Monson, Ingrid (1996). Saying something: Jazz improvisation and interaction. Chicago: The University of Chicago Press.

Oldfather, Penny, \& West, Jane (1994). Qualitative research as jazz. Educational Researcher, 23(8), 22-26.

Ricoeur, Paul (1984). Time and narrative, I. (Trans. K. McLaughlin \& Pellauer D.). Chicago: University of Chicago Press. 


\section{S. Bjerstedt}

Small, Christopher (1987). Music of the common tongue: Survival and celebration in African American music. Hanover, NH: University Press of New England.

Weick, Karl E. (1992). Agenda setting in organizational behavior: A theory-focused approach. Journal of Management Inquiry, I(3), I7I-I82.

Weick, Karl E. (1998). Improvisation as a mindset for organizational analysis. Organization Science, 9(5), $543-555$. 